\title{
Cyclic Agreement and Empty Slots in Pazar Laz*
}

\author{
ÜMITT ATLAMAZ \\ Boğaziçi University
}

\section{Introduction}

This paper discusses the compatibility of templatic morphology and cyclic agreement on verbal agreement prefixes in Pazar Laz. It is based on templatic morphology and introduces the following questions: Can agreement slots on verbal agreement remain empty through the steps of derivation? Is there insertion of a dummy element in cases when arguments are deficient in terms of agreement? The organization of the paper is as the following: It first introduces the relevant background information about templatic morphology and then, it presents data from Pazar Laz to show that it has a templatic morphology on verbs. In section 3 we propose a cyclic agreement model based on Bejar \& Rezac (2009) and discuss with relevant data. Section 4 summarizes and concludes the paper.

\section{$1 \quad$ Templatic Morphology \& Pazar Laz}

\subsection{Background}

Languages displaying an invariant order of morphemes on a word and mutual exclusivity of morphemes despite semantic compatibility have been claimed to have a templatic morphology (Stump 2006, Inkelas 1993). According to Spencer (1991) there are certain languages, where a word consists of a stem and some other obligatory affixes that go into certain slots defined by a template. One rather crucial work on templatic morphology which will help us determine whether Pazar Laz has a templatic morphology or not comes from Inkelas (1993), where she shows complementary appearance of certain morphemes despite semantic

\footnotetext{
* I would like to express my gratitude to Balkız Öztürk for her invaluable feedback and support throughout my experience with Pazar Laz, 37th annual meeting of BLS, and the current paper. It is also my duty to thank my Pazar informant İsmail Avcı Bucak'lişi for the Laz data he generously provided me with.
} 


\section{Cyclic Agreement and Empty Slots in Pazar Laz}

compatibility. As a result, she argues that certain slots are reserved for certain morphemes. Once a slot is filled with a morpheme, all the other candidates are blocked.

In light of Inkelas (1993), Stump (2006), and Spencer (1991), we observe that Pazar Laz verbs display properties of templatic morphology. Certain morphemes go into certain slots. Table (1) is a simplified version of a verb template in Pazar Laz, which is enough to serve the purpose of the current paper. ${ }^{1}$

(1)

\begin{tabular}{|c|l|l|c|c|c|c|l|}
\hline \multicolumn{2}{|c|}{ Prefixes } & Root & \multicolumn{4}{c|}{ Suffixes } \\
\hline I & \multicolumn{1}{|c|}{ II } & \multicolumn{1}{|c|}{ III } & IV & V & VI & VII & \multicolumn{1}{|c|}{ VIII } \\
\hline$P V$ & 1.IO Agr. & 1. Reflexive & Root & Series & Modal & Subj. & Number \\
& 2.DO & 2. Causative & & Marker & & Agr. & Agreement \\
& Agr. & 3. High & & & & & \\
& $\begin{array}{l}\text { 3. Subj. } \\
\text { Agr. }\end{array}$ & Applicative & & & & & \\
& 4. Low & & & & & \\
& Applicative & & & & & \\
\hline
\end{tabular}

Slot II in Table (1) houses a competition among the person agreement markers. These morphemes are in complementary distribution despite their semantic compatibility. As a result of this complementary distribution and the relative places of other morphemes on the verb we argue that Pazar Laz verbs show templatic morphology. Sentences (2), (3), and (4) show that slot II cannot be filled by more than one marker.

(2) Ma v-inçir-i

I.ERG 1Subj-swim-1sgPAST

'I swam.'

(3) $\mathrm{Ma}$ si ce-k-ç-i.

I.ERG you.NOM PV-2Obj-beat-1sgPAST

'I beat you.'

(4) ${ }^{*} \mathrm{Ma} \quad$ si

I.ERG you.NOM PV-1Subj-2Obj-beat-1sgPAST

'I beat you.'

Sentence (4) indicates that there is enough space for only one agreement marker in slot II in Pazar Laz despite the compatibility of 1Subj and 2Obj in terms of

See Öztürk \& Pöchtrager (2011) for the full represenation of slots that can appear on the verbal complex in Pazar Laz. 
meaning. Therefore we conclude that Pazar Laz shows templatic morphology for verbs.

\section{Verbal Agreement in Pazar Laz}

Before moving onto the theoretical discussion of cyclic agreement in Pazar Laz we would like to present some facts about Pazar Laz verbal agreement and some relevant data to be discussed in further sections.

Pazar Laz verbs carry person and number agreement, which are checked separately. Slot VII is reserved for structural subject (person only). Slot II houses a competition among arguments in terms of person agreement. Slot VIII houses number agreement. Sentences (5), (6) and (7) illustrate the agreement markers and their relevant places on a verb.
(5) $\mathrm{Ma} \quad \mathrm{si}$
I.ERG you.NOM(sg)
'I beat you (sg).'
ce-k-ç-i
PV-2Obj-beat-1sgPAST
(6) $\mathrm{Ma}$
t'k'va
I.ERG you .NOM(pl)
'I beat you (pl).'
ce-k-ç-i-t.
PV-2Obj-beat -1sgPAST-pl
(7) T'k'va
ma ce-m-ç-i-t
You.ERG (pl)
me.NOM
'You (pl) beat me.'

Given that person and number are encoded separately, in the absence of overt pronouns, we observe ambiguity. ${ }^{2}$

(8) ce-k-ç-i-t.

PV-2 Obj-beat -1sgPAST-pl
a. 'I beat you (pl).'
b. 'We beat you (sg).'
c. 'We beat you (pl).'

Since the main focus of the current paper is on the verbal agreement prefix, the following data will concentrate on slot II.

\footnotetext{
2 It should be noted that Pazar Laz is a pro-drop language and can drop both subjects and objects.
} 


\subsection{Slot II Competition}

As discussed before, slot II can house different morphemes depending on the argument structure of the verb and deficiencies in arguments. Morphemes that can fill slot II are listed on table (9). The subsequent sections will provide sentences with different arguments and agreement patterns to display the competition for slot II.

(9)

\begin{tabular}{|c|c|c|c|c|}
\hline & $\begin{array}{c}\text { Intransitive Subject } \\
\text { Transitive Subject (Agent) }^{\text {(Agheme) }}\end{array}$ & $\begin{array}{c}\text { Transitive Subject } \\
\text { (Experiencer) }\end{array}$ & DO & IO \\
\hline 1sg & $\mathrm{v} / \mathrm{f} / \mathrm{p} / \mathrm{b}$ & $\mathrm{m}$ & $\mathrm{m}$ & $\mathrm{m}$ \\
\hline 2sg & $\varnothing$ & $\mathrm{k} / \mathrm{g}$ & $\mathrm{k} / \mathrm{g}$ & $\mathrm{k} / \mathrm{g}$ \\
\hline 3sg & $\varnothing$ & $\varnothing$ & $\varnothing$ & $\varnothing$ \\
\hline 1pl & $\mathrm{v} / \mathrm{f} / \mathrm{p} / \mathrm{b}$ & $\mathrm{m}$ & $\mathrm{m}$ & $\mathrm{m}$ \\
\hline 2pl & $\varnothing$ & $\mathrm{k} / \mathrm{g}$ & $\mathrm{k} / \mathrm{g}$ & $\mathrm{k} / \mathrm{g}$ \\
\hline 3pl & $\varnothing$ & $\varnothing$ & $\varnothing$ & $\varnothing$ \\
\hline
\end{tabular}

Those morphemes listed under the second column on table (2) are usually referred to as 'v-set' whereas the rest are called as 'm-set' (Holisky 1991).

\subsection{Intransitive Verbs}

In sentences with intransitive verbs, slot II is filled with a 'v-set' marker unless the argument is deficient. Deficient, in this case, means that the argument does not have an overt agreement marker to fill slot II.

(10) v-inçir-i

1Subj-swim -1sgPAST

'I swam.'

(11) Ø-inçir-i

Ø- swim -2sgPAST

'You swam.'

(12) Ø-inçir-u

Ø- swim -3sgPAST

'He/She swam.'

3 See Öztürk 2008, 2010, Emgin 2009 and Öztürk \& Pöchtrager (2011) for the general case and agreement patterns of subjects and objects in relation to their theta-roles in Pazar Laz. 


\subsection{Transitive Verbs with Agentive Subjects I Competition Starts}

The competition for slot II surfaces in transitive sentences. Unless the object is deficient (i.e. third person), Slot II is filled with relevant DO maker. Otherwise, the subject fills Slot II with the relevant v-set agreement marker.

(13) $\mathrm{Si}$

You.ERG me.NOM PV-1Obj-beat-2sgPAST

'You beat me.'

(14) $\mathrm{Ma}$

I.ERG

'I beat you.'

(15) Ma

I.ERG

'I beat him.'

$$
\text { si ce-k-ç-i. }
$$$$
\text { you.NOM PV-2Obj-beat-1sgPAST }
$$

him

him/her.NOM

ce-p-ç-i.

PV-1Subj-beat -1sgPAST

ce- $\emptyset$ - ç-i

PV-Ø-beat -2sgPAST

(16) $\mathrm{Si}$

You.ERG him/her.NOM

'You beat him/her.'

\subsection{Ditransitive Verbs}

In sentences with ditransitive verbs, the privilege to fill slot II belongs to IO. When IO is deficient, the chance moves to DO and if that is deficient too, then ultimately the subject wins the competition to fill the agreement prefix slot.

$\begin{array}{llll}\text { Himu-k si } & \text { ma } & \text { m-o-dzir-u. } \\ \text { S/He-ERG } & \text { you.NOM } & \text { me.DAT } & \text { 1 IO-Appl-show-3sgPAST } \\ \text { 'S/He showed you to me.' } & & \end{array}$

(18) $\mathrm{Ma}$ si himu-s g-o-dzir-i.

I.ERG you.NOM her/him-DAT 2 DO-Appl-show-1sgPAST.

'I showed you to him.'

(19) Ma him himu-s v-o-dzir-i.

I.ERG her/him.NOM her/him-DAT 1Subj-Appl-show-1sgPAST.

'I showed him to him.'

(20) Himu-k him himu-s $\varnothing$-o-dzir-u.

S/he-ERG her/him.NOM her/him-DAT 3Subj-Appl-show-3sg PAST.

'S/He showed him to him.' 
Sentences (13)-(20) show that verbal prefix agreement is obtained through a cyclic fashion in Pazar Laz. Within this cyclic agreement process, a hierarchy of $1 / 2 \mathrm{IO}>1 / 2 \mathrm{DO}>1 / 2 \mathrm{Subj}>3 \mathrm{IO} / \mathrm{DO} / \mathrm{Subj}$ agreement is observed (See Öztürk \& Pöchtrager [2011] for details). Nevertheless, this is not the case for all instances of verbal prefix agreement.

\subsection{Non-Agentive Transitive Verbs with Dative Experiencers}

The following patterns seem not to abide by the cyclic agreement observed in sentences (13) - (20).

\subsubsection{Dative Experiencer-oriented Pattern}

In this pattern, dative argument governs the agreement prefix (slot II). Nominative theme, acting as DO does not agree at all. Dative argument in such sentences behave as if it is an indirect object (Harris 1982) and fills the prefix position with its relevant object agreement marker (m-set) rather than the subject agreement marker (v-set). Agreement suffix is always in 3rd person, but it can reflect the plurality of the dative experiencer. This indicates the absence of a thematically marked structural subject. The default 3rd person agreement might imply the presence of a covert expletive subject, fulfilling the structural subject role. See Öztürk $(2008$, 2010) for a classification of different subject types in Pazar Laz.

$\begin{array}{lll}\text { Himu-s } & \text { ma } & \text { g- } \emptyset \text { - o- chondr-u. } \\ \text { S/he-DAT } & \text { I.NOM } & \text { PV- } \emptyset \text {-Appl-forget-3sgPAST }\end{array}$

'S/He forgot me.'

(22) Sk'u We/DAT you/they.NOM 'We forgot you/them.'

(23) $\mathrm{Si}$ $\mathrm{Si} \quad$ sk'u/hini
You.DAT(sg.) $\quad$ we/they.NOM
'You forgot us/them.'

(24) Hini-s They-DAT him/ma/hini she/I/they.NOM

'They forgot us/you/them.' go-m-o-chondr-es

PV-1 Obj-Appl-forget -3sgPAST-pl

go-g-o-chondr-u PV-2 Obj-Appl-forget-3sgPAST

g- $\emptyset$-o-chondr-es

PV- Ø-Appl-forget-3plPAST 


\subsubsection{Nominative Theme-Oriented Pattern ${ }^{4}$}

This is the pattern where nominative theme is focused. When the dative argument is deficient (3rd person) and the nominative theme DO is 1st or 2nd person then it is possible for the DO to fill Slot II. In this case dative argument does not agree at all. The DO behaves as if it is the subject and fills the prefix position with its relevant subject agreement marker (v-set) rather than the object marker (m-set). Agreement suffix can then also reflect the features of the DO.

$\begin{array}{lll}\text { Himu-s } & \text { ma } & \text { go-v-o-chondr-i } \\ \text { S/he-DAT } & \text { I.NOM } & \text { PV- } 1 \text { Subj-appl-forget-1sgPAST } \\ \text { She forgot me. (me is focused) } & \end{array}$

\section{Cyclic Agreement}

Anderson (1992) argues that Georgian, a language of the same family as Pazar Laz, displays a cyclic agreement on verbs. Agreement happens in a cyclic way through a list of arguments whose Morphosyntactic Representation is:

$$
\left[\mathrm{T} / \mathrm{A}, \mathrm{F}_{\mathrm{SBJ}}\left[\mathrm{F}_{\mathrm{IO}}\left[\mathrm{F}_{\mathrm{DO}}\right]\right]\right]
$$

In this model, the agreement cycle starts from the innermost layer and goes towards the outer layers until the slot is filled with an agreement morpheme. In cases when an argument is deficient in terms of agreement, it leaves a dummy element ' $\varnothing$ '. Then the agreement cycle moves further to find an agreeing argument that will fill the relevant slot.

Based on figure (26) T/A which is a verb screeve, carrying basic verb and tense meaning, starts the agreement from the DO. When DO is deficient, ' $\varnothing$ ' is inserted and then the chance to fill the relevant slot moves to IO. In cases when IO is deficient too, finally, subject agrees with the verb. In this model, DO agreement is compulsory whereas, the rest is optional. Anderson's obligatory DO rule is:

Copy features and referential index from a direct object NP to the verb if present; if there is no Direct Object, add ' $\varnothing$ '

(Anderson 1992)

The most relevant point of this model to the current paper is the insertion of

$4 \quad$ This pattern is beyond the scope of the current paper since it has a focused reading and one needs to determine where the arguments are on the syntactic tree when focused. See Öztürk (2011) for a syntactic account of these constructions, where it is argued that DO actually acts as the structural subject of the sentence. 


\section{Cyclic Agreement and Empty Slots in Pazar Laz}

dummy placeholders in cases when an argument is deficient. This suggests that one slot can be filled by placeholders and morphemes at the same time.

In section 1 we argued that Pazar Laz has a templatic morphology based on Inkelas (1993). The main rationale for such a claim is the complementariness of some morphemes despite semantic compatibility. Now, bringing Pazar Laz facts and Anderson's (1992) claims on cyclic agreement together, we observe a problem. Anderson's claim of inserting dummy placeholders does not agree with the fact that once a slot is filled with a morpheme it cannot host another one. If a dummy placeholder is inserted in cases of deficient arguments, then it should block other arguments from kicking in, since there is room for only one agreement marker. As a consequence we, like Anderson (1992), argue that agreement happens through a list of arguments, but unlike him, put forth that agreement slots remain empty until they are filled with the agreement marker of a non-deficient argument.

Once we pose such a claim, we come across with some problem sentences like (21), where 1st person theme is not deficient but cannot fill slot II with its relevant agreement marker. In order to suggest a solution to this problem we refer to Bejar \& Rezac's (2009) cyclic agreement approach to Georgian.

Bejar and Rezac (2009) suggest a cyclic agreement model for Georgian based on Distributed Morphology. In this model, Agreement head searches the local domain first and then expands its domain towards the Spec of higher phrase in the subsequent cycles. This approach, together with Pylkännen's (2000) applicative argument, explains the cyclic agreement in Pazar Laz verbal agreement prefixes.

Pylkännen (2000) argues for the existence of two types of applicative constructions, which are High applicatives and Low applicatives. High applicatives denote a relation between an event and an individual, selecting a VP as their complement. Low applicatives, on the other hand, denote a relation between two individuals, taking DPs as their complements.

a) High Applicative

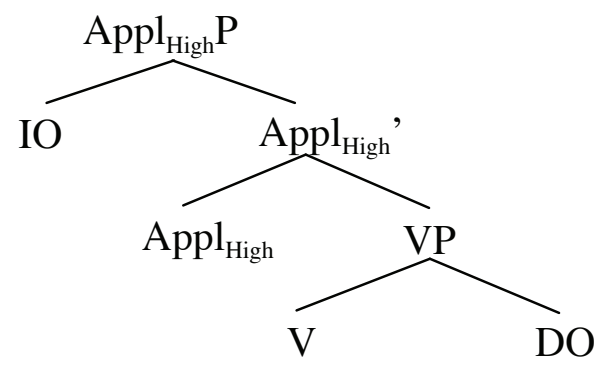

b) Low Applicative

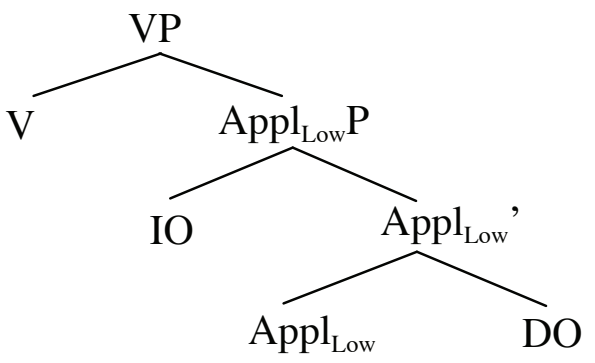

(McGinnis 2001)

Öztürk (2011) and Demirok (2011), both independently, argue that Pazar Laz possesses both types of applicative constructions. Ditransitives qualify as low 
applicatives, whereas sentences with dative experiencers as in (21) are high applicatives (Öztürk 2011, Demirok 2011).

In the light of Bejar \& Rezac (2009)'s cyclic agreement approach and Öztürk (2011) and Demirok (2011)'s applicative analyses, we propose the following agreement rule and discuss the relevant data based on this rule.

Rule Agree: In cases when there is an applicative construction, applicative head takes care of the agreement. Applicative head probes for an agreeing argument within its local domain first, then extends its domain to higher phrases in cases of deficiencies.

\subsection{Ditransitives}

Sentences (28)-(31) and figure (32) illustrate and support the rule proposed above.

(28) m-o-dzir-u.

1 IO-Appl-show -3sgPAST

'He showed you to me.'

(29) g-o-dzir-i.

2 DO-Appl-show-1sgPAST .

'I showed you to him.'

(30) v-o-dzir-i.

1Subj-Appl-show-1sgPAST .

'I showed him to him.'

(31) Ø-o-dzir-u.

Ø -Appl-show-3sgPAST .

'S/He showed him to him.'

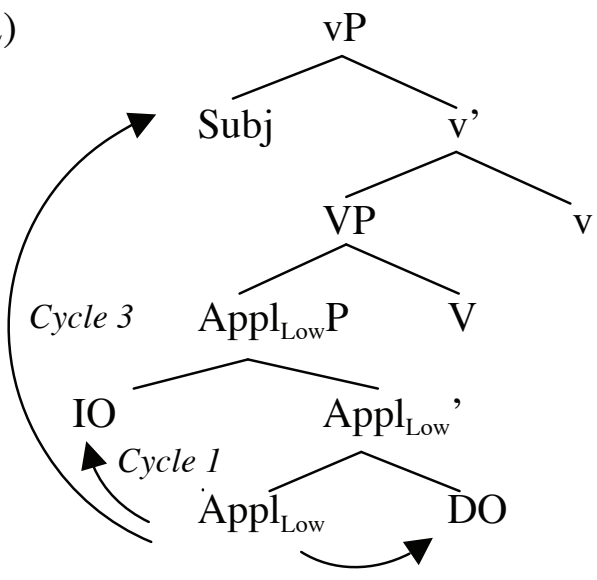

Cycle 2 
In ditransitive constructions, we assume that $\mathrm{Appl}_{\text {Low }}$ head takes care of the agreement in Slot II. In the first cycle, Appl $_{\text {Low }}$ head looks at it specifier and agrees with the argument on this node, which is an IO in Pazar Laz. Sentence (28) is an example of Cycle 1 agreement. When the IO is deficient, then Cycle 2 happens and $\mathrm{Appl}_{\text {Low }}$ head agrees with DO as in sentence (29). When both IO and DO are deficient, Cycle 3 expands the agreement domain towards the specifier of higher phrase which is the subject in this case (Sentence (30)). Sentence (31) illustrates the cases when all the arguments are deficient.

Öztürk (2011) claims that applied arguments in Spec, ApplPs in Pazar Laz check inherent dative case. Therefore, the reason why the $\mathrm{Appl}_{\mathrm{Low}}$ head first searches for the argument in its Spec, is to ensure a case and agreement match. That is, Appl head agrees with the argument whose case it checks. However, when the argument in its Spec is not compatible for agreement then it looks down for another argument within its domain, which then leads to a case and agreement mismatch in the same lines as Bhatt (2005).

\subsection{Dative Experiencer - Oriented Pattern}

Dative experiencer-oriented pattern seem a bit problematic at first sight, since slot II remains empty even though theme is not deficient. In such sentences, only dative experiencer can fill slot II.

$$
\begin{array}{lll}
\text { Sk'u } & \text { si/hini } & \text { go-m-o-chondr-es } \\
\text { We.DAT } & \text { you/they.NOM } & \text { PV-1 Obj - Appl-forget -3plPAST } \\
\text { 'We forgot you/them.' } &
\end{array}
$$

$\begin{array}{lll}\text { Hini-s } & \text { him/ma/hini } & \text { g- } \emptyset \text {-o-chondr-es } \\ \text { They-DAT } & \text { she/I/they.NOM } & \text { PV- } \varnothing \text {-Appl-forget-3plPAST } \\ \text { 'They forgot us/you/them.' } & \end{array}$

Sentences with dative experiencer-oriented pattern are high applicative constructions and have the following structure:

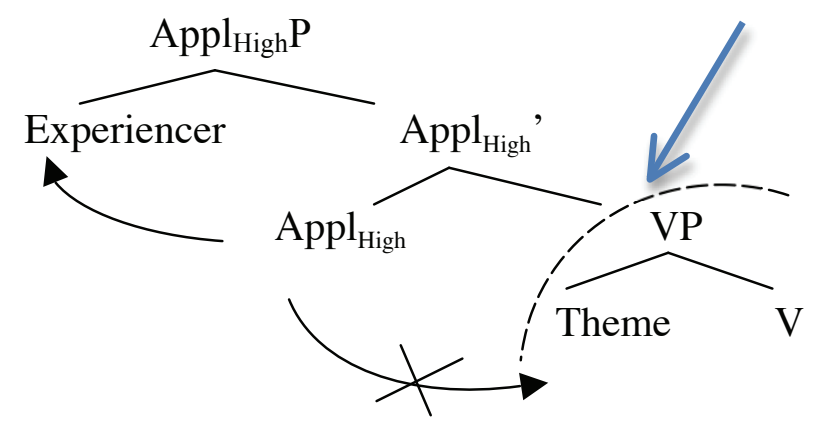


We assume that $\mathrm{Appl}_{\text {High }}$ head is responsible for agreement in high applicative constructions. It probes for an agreeing argument in its specifier. When the argument in its specifier is deficient, it probes down for another potential argument, which is the theme in this case. Nevertheless, theme is not in the local domain of $\mathrm{Appl}_{\text {High }}$ head. VP functions as a blocking node. Therefore, we argue that such sentences do not pose any threat to the validity of the agreement rule we propose.

\subsection{Agentive Transitives}

Cyclic agreement in agentive transitives happens in a similar way with some differences. The first difference is that there is no applicative phrase in agentive transitive sentences. Therefore we assume that $v$ head is responsible for the agreement. The second difference is related to the order of the cycles. In applicative constructions, first cycle would start with checking the specifier; whereas, in agentive transitive constructions this priority belongs to the $\mathrm{DO}$ which sits on a complement position as opposed to the subject which occupies the specifier of vP. It should also be noted that VP does not block the agreement between $\mathrm{v}$ head and theme, while it does so in Appl-theme agreement.

$\begin{array}{ll}\text { Ma si } & \text { ce-k-ç-i. } \\ \text { I.ERG you.NOM } & \text { PV-2Obj-beat -1sgPAST } \\ \text { 'I beat you.' } & \end{array}$
Ma him
I.ERG him/her.NOM
ce-p-ç-i.
'I beat him.'
PV-1Subj-beat -1sgPAST

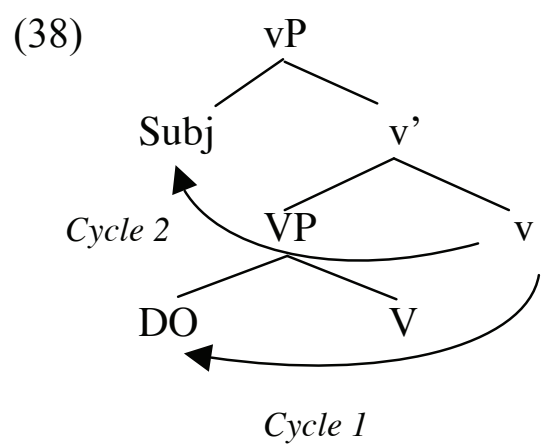

We propose that the reason for such an ostensible inconsistency is due to case relations between these heads and arguments. The case checking functional head has the priority in terms of agreement. Applicatives check the inherent case of the argument in their Spec position, therefore in their first cycle they first try to agree 


\section{Cyclic Agreement and Empty Slots in Pazar Laz}

with the NP in their Spec and move on to other cycles if that NP is deficient. Similarly, $v$ head checks the case of the theme and tries to agree with it in the first cycle. Case relation between $\mathrm{v}$ and theme also resolves the blocking problem caused by VP. This implies that case and agreement can be dissociated from one another under certain conditions in Laz in the same line as Bhatt (2005). See Öztürk (2011) for details of case checking in Pazar Laz.

\subsection{Nominative Theme-Oriented Pattern}

Our proposal seems to hold based on Öztürk (2011), where it is claimed that, in nominative theme-oriented pattern, direct objects act as structural subjects when focused. Focused theme raises to a node where it is checked case by T. ${ }^{5}$ As a result of this raising, it escapes the VP blockage and enters into agree relation with the applicative head which is not possible in dative experiencer-oriented pattern. Since it case checks with T, the agreement slot II is filled by a v-set marker.

\subsection{Intransitives}

In intransitives, $\mathrm{v}$ head agrees with the sole argument using $\mathrm{v}$-set agreement markers. ${ }^{6}$ Since there is only one argument there is only one cycle for agreement.

\section{I.ERG $\quad$ 1Subj-swim -1sgPAST}

'I swam.'

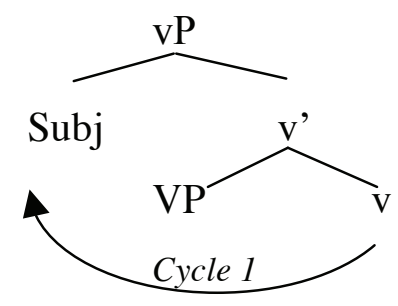

5 This node could be Spec,v or one of the multiple specifiers of the applicative head. Nevertheless, as stated earlier, this is beyond the scope of the current paper and requires further research.

6 Öztürk 2011 proposes that $\mathrm{v}$-set reflects presence of case-checking with $\mathrm{T}$ head, whereas $\mathrm{m}$-set indicates case-checking with the functional heads below vP, such as with applicatives or the $\mathrm{v}$ head. 
Ümit Atlamaz

\section{Conclusion}

In this paper, we analyzed Pazar Laz verbal agreement prefixes and put forth that cyclic agreement is compatible with templatic morphology based on a distributed morphology point of view. Agreement slots remain empty until they are filled by an agreement marker of a non-deficient argument. Another important proposal of the current paper is that in the first cycle, an agreement head tries to agree with the argument it checks case with. Pazar Laz agreement system also shows that morphology is shaped depending on syntax (argument structure, deficiencies in arguments, etc.) and therefore we claim that morphology is post-syntactic as assumed within the Distributed Morphology framework (Halle and Marantz 1993, 1994 and the following work).

\section{References}

Anderson, S. R. 1992. A-Morphous Morphology. Cambridge [England] ; New York: Cambridge University Press.

Bejar, S. \& Rezac, M. 2009. Cyclic Agree. Linguistic Inquiry, Vol 40 (pp. 35-73). MIT Press.

Bhatt, R. 2005. Long Distance Agreement in Hindi-Urdu. Natural Language and Linguistic Theory, 23.4:757-807.

Demirok, Ö. F. 2011. A Minimalist Analysis of Laz-Georgian Applicatives. Ms. Boğaziçi University.

Emgin, B. 2009. Complementation patterns in Pazar Laz. MA thesis. Boğaziçi University.

Halle, M. and A. Marantz. 1993. Distributed Morphology and the Pieces of Inflection. In K. Hale and S. Jay Keyser (eds.), The View from Building 20; Essays in Honor of Sylvain Bromberger, 111-176. MIT Press.

Halle, M. and A. Marantz. 1994. Some Key Features of Distributed Morphology. In A. Carnie, et. Al (eds.), Papers in Phonology and Morphology, 275-288. MITWPL 21.

Harris, A. C. 1981. Georgian Syntax: A study in relational grammar. Cambridge University Press. 


\section{Cyclic Agreement and Empty Slots in Pazar Laz}

Harris, A. C. 1982. Georgian and the Unaccusative Hypothesis, Language 58: 290-306.NY.

Holisky, D. A. 1991. Laz. In A. C. Harris (Eds.), The Indigenous Languages of the Caucasus. Vol. 1. The Kartvelian Languages. (pp. 395-472). New York: Caravan Books.

Inkelas, S. 1993. Nimboran Position Class Morphology. Natural Language and Linguistic Theory, 559-624.

Kojima, G., Bucaklişi, İ.A., and Uzunhasanoğlu, H. 2003. Lazuri Grameri. (Explanations in English G. Kojima, Eylem Bostanc1 ). İstanbul: Chiviyazıları

McGinnis, M. 2001. Phases and the syntax of applicatives. NELS 31.

Öztürk, B. 2008. The Loss of Case System in Ardesheni Laz and its morphosyntactic consequences. Talk given at Morphological Variation and Change in the Languages of the Caucasus. 13th International Morphology Meeting. University of Vienna. Austria.

Öztürk, B. 2010 Subjects in Pazar and Ardesheni Laz. Dilbilim Araştırmaları. Boğaziçi University Press.

Öztürk, B. 2011 Low, High and Higher Applicatives: Evidence from Pazar Laz. Talk given at the $21^{\text {st }}$ Colloquium on Generative Grammar, University of Seville, Spain.

Öztürk, B. and M. Pöchtrager (eds.). 2011. Pazar Laz. LINCOM Europa.

Pylkkänen, L. 2002. Introducing Arguments. Ph.D. Thesis. MIT. Cambridge, MA. Spencer, A. 1991. Morphological Theory: an introduction to word structure in generative grammar . Oxford, UK ; Cambridge, Mass., USA: Basil Blackwell.

Stump, G. 2006. Template Morphology. In K. Brown (Eds)., Encyclopedia of Language and Linguistics, Vol 12 (pp. 559-563). Oxford: Elsevier.

Ümit Atlamaz

18 Seminary Place

New Brunswick, NJ 08901-1184

umit.atlamaz@rutgers.edu 